\title{
COLÉGIO ESTADUAL PANDIÁ CALÓGERAS: QUEBRANDO BARREIRAS LINGUÍSTICAS
}

\begin{abstract}
Louise Mesquita Costa é professora da Educação Básica, especialista em Língua Portuguesa e Tradução e mestranda em Estudos de Linguagem na UFF. Além disso, possui curso de Atendimento Educacional Especializado com foco em alunos surdos.

E-mail: Louise.mesquita@gmail.com
\end{abstract}

Resumo A inclusão é um desafio que implica mudar a escola como um todo. Em 2008, o Colégio Estadual Pandiá Calógeras (CEPC), situado no Município de São Gonçalo, RJ, precisou lidar com uma situação completamente nova: a chegada de alunos surdos. Naquele ano, a barreira linguística e cultural resultou em uma inclusão excludente. No entanto, o CEPC conseguiu contornar essa realidade. Como? Este relato de experiência descreverá a implementação de um projeto cujo objetivo foi ensinar libras e cultura surda a toda comunidade escolar, a fim de possibilitar a interação entre surdos e ouvintes e valorizar e respeitar a diferença. Os resultados superaram as expectativas e a avaliação foi positiva.

Palavras-chave: Educação inclusiva.

Barreira linguística e cultural. Libras.

A Declaração Mundial sobre Educação para Todos (1990) aponta para a necessidade de se assumir um compromisso efetivo para superar as disparidades educacionais. De fato, é preciso encurtar a distância entre a escola que se tem e a escola que se quer. Como um todo, o Colégio Estadual Pandiá Calógeras, localizado no município de São Gonçalo, estado do Rio de Janeiro, buscou isso.

O CEPC é composto por cerca de 230 funcionários e 3.000 alunos. A unidade busca melhorias na qualidade de ensino e inovações em sua prática pedagógica, criando condições para uma educação de inclusão e equalizadora. Nos últimos anos, vários projetos foram elaborados e alguns deles tiveram projeção internacional. Segundo o Projeto Político Pedagógico do CEPC, "a escola que desejamos é espaço de cada um constituir-se como grupo, aprender a ser nós, compartilhar, cooperar". 
Em 2008, porém, o colégio se deparou com uma situação completamente nova: a chegada de três alunos surdos. Naquele ano, as barreiras linguística e cultural levaram a uma inclusão excludente. Esse problema foi levantado por toda comunidade escolar. Era tempo de mudança e transformação. Conforme explicitado por Maura Lopes (2005, p. 1), uma escola inclusiva exige redefinições e uma outra estrutura; isso implica em desarrumar o que imaginávamos estar arrumado.

Educadores e alunos precisavam aprender Libras. A direção solicitou verba à Secretaria do Estado de Educação, através de projeto. O objetivo era que docentes e funcionários tivessem acesso a um curso gratuito de Libras no próprio colégio. Em relação aos alunos, surgiu a ideia de lhes ensinar Libras e Cultura Surda no tempo destinado à disciplina de Atividade Complementar. No efetivo da escola, havia uma professora de Língua Portuguesa com fluência em Libras. A ela caberia a tarefa de reger essa disciplina na turma em que havia surdos. Sobre essa experiência, será o presente relato.

\section{2) Equipe Responsável pela Experiência}

Louise Mesquita Costa, professora de português e de libras, elaborou e aplicou a proposta. Em 2005, ela começara a trabalhar como intérprete voluntária na comunidade. Mais tarde, trabalhou na UFRJ como intérprete e fez parte do Laboratório de Pesquisa e Ensino da Libras (LAPEL). Em 2008, foi chamada para ser intérprete no Instituto Nacional de Educação de Surdos (INES) e atuou na pós-graduação de Surdez e letramento em anos iniciais para crianças e EJA.

O contato com surdos e a experiência nessas duas instituições desenvolveu nessa docente uma sensibilidade para questões relacionadas à educação de surdos. Seu desejo era quebrar barreiras e proporcionar uma educação equalizadora que amenizasse disparidades.

Assim, um projeto foi criado e levado a Silvana Guimarães, coordenadora pedagógica, e a Bianca de Macedo Abreu, diretora adjunta do CEPC. Elas aprovaram a proposta e se tornaram responsáveis pelo suporte técnico-administrativo. Dessa forma, a equipe responsável foi composta de três pessoas.

\section{3) Público-alvo}

O público-alvo deste projeto foi os 36 alunos do $6^{\circ}$ ano do Ensino Fundamental, que compunham a turma 601. Essa era, em 2009, a única classe inclusiva do CEPC. Sem interação com "o outro", com a diferença, a formação desses alunos seria incompleta.

Além destes, de maneira mais generalizada, outros dentro da comunidade escolar foram beneficiados por meio de trabalhos expostos e palestras elaboradas dentro deste projeto. E superando o proposto, os alunos ouvintes da classe 601 se tornaram agentes multiplicadores, disseminando a Libras e a cultura surda. 


\section{4) Objetivo}

Um dos objetivos do ensino de Libras e cultura surda na disciplina de Atividade Complementar era possibilitar a interação entre surdos e ouvintes. Ao tomar essa ação, a escola estaria oportunizando à sua comunidade espaços de participação, inclusão, conhecimento, troca de experiências visando o crescimento individual e grupal dos envolvidos. Segundo Paula Botelho, as pessoas tendem a se reunir com seus iguais em idade, classe econômica, nível de escolaridade; a conveniência é um fator que dita a coesão a determinado grupo, constituindo-o como um endogrupo. Não há, assim, necessidade de voltar-se para exogrupos a fim de buscar companhia. Em relação aos surdos, a necessidade de contato com os ouvintes (exogrupo) não é evidente, uma vez que parece ser mais confortável estar entre os que compartilham e são fluentes na mesma língua, a língua de sinais. (BOTELHO, 2005, p. 24)

Observou-se que isso realmente ocorreu em 2008. E esse era o desafio do CEPC: atenuar o afastamento entre surdos e ouvintes. Quebrando a barreira linguística, a troca de experiências poderia ocorrer. Isso levaria a uma aproximação e a um crescimento individual e grupal de todos os envolvidos.

Outro objetivo desse projeto era contribuir para formar cidadãos críticos e solidários, que respeitassem as diferenças sociais e culturais. Segundo Vigotsky (1989), não é a surdez que define o destino das pessoas, mas o resultado do olhar da sociedade sobre a surdez.

Era necessário respeitar o sujeito surdo. Todavia, para que isso acontecesse, era preciso conhecer sua cultura. Só assim estigma, preconceito e formações imaginárias seriam dissipados.

\section{5) Descrição Detalhada da Experiência}

Primeiro dia de aula. Olhares discretos espiavam os novos alunos. Burburinhos e comentários eram ouvidos. Curiosidade e receio se misturavam. $\mathrm{O}$ afastamento era evidente. A professora, como mediadora, introduziu a turma no universo surdo. Ela lhes explicou que os surdos eram como estrangeiros. Eles não falavam o português, mas se a classe aprendesse Libras, poderia se comunicar com eles. Ela também ensinou que em língua de sinais, cada pessoa tinha um nome e um sinal (nome em Libras), e que este era dado por um surdo. Depois disso, ela entregou o alfabeto manual a todos. Em seguida, dividiu a turma em seis grupos. Cada surdo seria responsável por um grupo. Eles deveriam ajudar os demais alunos a reproduzir o alfabeto com as mãos. Também tinham a tarefa de em uma semana criar um sinal para cada colega. Ao término, não havia mais tensão. Todos estavam animados. Muitos se arriscavam a se comunicar por meio de mímicas.

Segundo dia de aula. A professora foi cercada por vários alunos que queriam mostrar o novo nome que eles haviam recebido: o sinal em Libras. Passado esse momento, ela pediu que a turma se dividisse em grupos de alunos ouvintes e em um grupo de alunos surdos. O que tenho curiosidade de saber a respeito do outro? Cada equipe deveria formular três perguntas. E estas foram muitas. A classe estava ansiosa. Contudo, a professora não deu 
uma resposta imediata. Ela ensinou aos alunos ouvintes o modo de se fazer àquelas perguntas em Libras. Ela só interpretou as respostas.

Durante dois meses, o conhecimento a respeito do universo surdo foi aprofundado. Concomitantemente, alunos ouvintes incorporavam os sinais. Era chegado o momento de transmitir esse aprendizado a toda comunidade escolar. Perguntas pertinentes foram escolhidas. Os surdos lapidaram as respostas. Uma palestra mediada pela professora seria dada a todo o CEPC. Alunos ouvintes entrevistariam em libras os alunos surdos. O que era curiosidade de um, poderia ser de outros. Isso ocorreu na Semana de Integração Pedagógica. Todos estavam bem preparados e a iniciativa repercutiu positivamente em todo o turno da manhã.

\section{6) Resultados}

Os resultados mostraram que os objetivos pretendidos foram alcançados. E superaram as expectativas. Com o ensino de Libras e cultura surda, o afastamento desapareceu. $\mathrm{O}$ receio deu lugar ao desejo de querer estar junto dos indivíduos surdos e de querer aprender Libras.

O ensino do gênero carta pessoal faz parte do currículo mínimo do $6^{\circ}$ ano. Assim, pouco depois de se dar início ao projeto, a professora de língua portuguesa pediu aos alunos que estavam participando da proposta que escrevessem uma carta. Nela eles deveriam contar a um amigo como era estudar em uma classe inclusiva.

Os trechos abaixo são fragmentos dessas cartas e comprovam o sucesso do projeto:

1. Carta 1 Querida

$L$,

Você não vai acreditar, no começo do ano, 6 alunos eram surdos $e$ mudos, no começo me perguntei como me comunicaria com eles, até que um dia tive a primeira aula de Aticon e achei muito legal. Agora já consigo um pouco me comunicar com eles...

2. Carta 2 Querida

$G$,

G aqui na minha sala tem pessoas especiais. É muito legal. Eu fiquei surpresa por que eu nunca tive essa oportunidade e a agora tenho. Eu estou gostando.

Abraços,

A.

P.S.: Eu estou alegre de esta aprendendo libras e se você quiser aprender eu te ajudo.

3. Carta 3 Querida

$S$,

S essa escola esta cada vez ta ficando melhor. Na minha sala tem 6 surdo e mudo. Eu estou aprendendo a falar com eles. A professora Autor é muito legal. Ela ta ensinando a falar com eles. É muito legal. 


\section{Beijos,}

$M$.

Essa iniciativa também contribuiu para um clima de união e cooperação. Na hora do intervalo, surdos e ouvintes se misturavam. Alunos ouvintes de outras turmas também se aproximavam e alguns, inclusive, pediam para mudar de turma. Nos trabalhos escolares de outras disciplinas, ouvintes convidavam o surdo para participar do grupo deles. Mais tarde, quando um intérprete faltou, um aluno ouvinte se ofereceu para interpretar o conteúdo para os surdos.

Estigma, preconceito e formações imaginárias não aconteceram. Todos tinham muitas perguntas e elas foram respondidas. Em muitos casos, o preconceito surge do surdo em relação a ele mesmo. Ele sente que está em uma posição inferior por não ler nem escrever. Entretanto, isso não ocorreu com os alunos do CEPC. As aulas de Atividade Complementar lhes mostraram que eles tinham um saber que o outro não tinha. Isso aumentou a autoestima deles. Havia troca de conhecimento.

\section{7) Avaliação}

A avaliação da proposta foi positiva. O público-alvo aderiu à ideia e todos os objetivos foram alcançados.

No entanto, o projeto foi descontinuado nos anos posteriores por questões administrativas. A escola não teve autorização pela regional metropolitana para manter a professora em tela na disciplina de Atividade Complementar em decorrência da carência de professores no estado. Portanto, a referida docente teria que atuar e sua disciplina de origem: Língua Portuguesa.

\section{8) Considerações Finais}

Como Maura Lopes (2005, p. 2) aponta, a inclusão não é um único projeto a ser pensado, mas é o nome que se dá para um conjunto de projetos que devem estar articulados entre si e permanentemente sendo postos em questionamento. Esse relato de experiência foi um dos projetos criados pelo CEPC, que partiu do seguinte pressuposto: é preciso atender a todos com qualidade. No caso dos indivíduos surdos, para que isso fosse alcançado, seria necessário criar meios para que houvesse interação entre surdos e ouvintes, além de respeito à diferença.

Os projetos do CEPC são mostra de uma comunidade que acredita no sonho possível, na possibilidade de transformação da realidade e se coloca a favor de uma globalização solidária, cooperativa e cada vez mais includente. Atualmente, o CEPC atende a cerca de 30 alunos surdos em todos os anos de escolaridade. 


\section{Referências}

BOTELHO, Paula. Linguagem e letramento na educação dos surdos - Ideologias e práticas pedagógicas. Belo Horizonte: Autêntica, 2005.

BRASIL. Declaração Mundial sobre Educação para Todos: plano de ação para satisfazer as necessidades básicas de aprendizagem. Jontiem-Tailândia: UNESCO, 1990.

LOPES, M. C. Inclusão escolar: desarrumando a casa. Jornal _H - Suplemento _H na Escola, Novo Hamburgo (RS), p. 2-2, 12 nov. 2005.

VIGOTSKY, L. S. Linguagem e Pensamento. São Paulo: Martins Fontes, 1989.

Enviado em 10 de setembro de 2016. 